LBNL-40292

Published in Indoor Air 7: 55-63, 1997

\title{
Air Change Effectiveness and Pollutant Removal Efficiency During Adverse Mixing Conditions
}

\author{
William J. Fisk ${ }^{*}$, David Faulkner ${ }^{*}$, Douglas Sullivan*, and Fred Bauman ${ }^{+}$ \\ *Indoor Environment Program, Energy and Environment Division \\ Lawrence Berkeley Laboratory, Berkeley, CA \\ ${ }^{+}$Center for Environmental Design Research \\ University of California, Berkeley, CA
}

December 1995

\begin{abstract}
The air change effectiveness (ACE), an indicator of the indoor airflow pattern, was measured in twenty-six laboratory experiments. Ventilation air was supplied through inductiontype diffusers located in the ceiling and removed through a ceiling-mounted return grille. The tracer gas stepup measurement procedure was employed. In five of the experiments, pollutant removal efficiencies were also measured for simulated pollutant emissions from the floor covering and for simulated emissions from occupants. In experiments with heated supply air, supply air flow rates typical of the minimum supply flow rates of VAV ventilation systems, and $100 \%$ outside air, the ACE ranged from 0.69 to 0.89 . These results indicate that significant short circuiting of ventilation air between the supply air diffuser and return air grille does occur under these adverse conditions. Mechanical recirculation of air, such that the supply air contained approximately $50 \%$ outside air, increased the ACE by about 0.05 . When the supply air was cooled, the ACE ranged from 0.99 to 1.15, adding to existing evidence that short circuiting is rarely a problem when the building is being cooled. The pollutant removal efficiency for simulated pollutant emissions from the floor covering $\left(\mathrm{PRE}_{\text {floor }}\right)$ was strongly correlated with $\operatorname{ACE}\left(\mathrm{R}^{2}=0.98\right)$ and the values of PRE floor were within approximately 0.1 of the values of ACE. The pollutant removal efficiency for simulated pollutant emissions by occupants varied between workstations and was not as well correlated with the ACE.
\end{abstract}

Key Words: air change effectiveness, buildings, efficiency, exposure, pollutant, ventilation

\section{Introduction}

Air quality at the breathing zone within buildings is influenced by the indoor flow patterns of air and pollutants. Conceptually, the indoor airflow pattern between supply air diffusers and return air grilles can range between extensive short-circuiting flow and a perfect displacement (piston-like) flow of air. In between these extremes is the case of perfectly mixed

air. In a typical office building with air supplied and removed at ceiling level, the short circuiting 
flow pattern is inefficient in supplying fresh air to occupants and inefficient in removing pollutants generated in the lower occupied portion of the building. Perfect mixing within rooms is often the design intent. An upward displacement flow can, in some situations, be more efficient than perfect mixing.

Researchers use a variety of "ventilation efficiency" parameters to characterize indoor airflow patterns. One parameter is the air change effectiveness (ACE) defined as the age of air that would occur throughout the building if the indoor air was perfectly mixed divided by the average age of air where occupants breathe (ASHRAE 1992). The age of air at a particular location is the average time elapsed since molecules of air at that location entered the building from outdoors. Because the average age of air exiting the building is identical to age of air that would occur throughout building ${ }^{*}$ if the indoor air was perfectly mixed (Sandberg and Sjoberg 1983), the ACE is also the exhaust-air age divided by the average age of air where occupants breathe. A short circuiting flow pattern decreases the exhaust-air age and causes the ACE to be smaller than unity. Perfect mixing results in an ACE of unity. A displacement flow pattern is indicated by an ACE greater than unity.

Pollutant removal efficiencies, although rarely used, are more direct indicators than ACE of the effectiveness of the ventilation process in controlling occupant exposure to indoorgenerated air pollutants. We define the pollutant removal efficiency (PRE) as the time-average concentration of pollutant in exhaust air divided by the time-average concentration where occupants breathe. The PRE is a function of the locations of pollutant sources and the nature of the pollutant emission process, e.g., emitted with or without momentum, and a function of the indoor air flow pattern.

For several years, a portion of the building engineering community has expressed their concerns that short circuiting air flow patterns are common, serious problems that adversely affect indoor air quality and lead to occupant complaints. Short circuiting is especially thought to be a problem when variable-air-volume (VAV) ventilation systems supply air at low flow rates (because the low supply flows reduce mixing via entrainment of room air in the supply jets) and when the supply air is warmer than room air ( because the warm buoyant supply air jet may stay near the ceiling and short circuit to the ceiling-level return grille). There are anecdotal reports that engineers avoid energy efficient VAV systems because of this concern while others assume that the ACE is significantly lower than unity and increase outside air supply rates accordingly.

The majority of existing data from office buildings with conventional ventilation systems, with ceiling-level supply and return of air and induction-type supply diffusers, indicate that the ACE is close to unity, e.g., between approximately 0.8 and 1.2, and often indistinguishable from unity given the estimated measurement uncertainty (Fisk and Faulkner 1992; Persily 1986; Persily and Dols 1989; Seppanen 1986; Olesen and Seelen 1992). However, very few data are available on ACE for the suspected adverse operating conditions of heated supply air and/or low supply flow rates. The primary objective of the measurements described in this paper is to determine values of ACE and PRE for these adverse operating conditions. A secondary objective is to explore the relationship between ACE and PRE. Bauman et al. (1995) have completed a complementary study of air velocities and thermal comfort conditions for the same set of operating conditions.

\footnotetext{
*xcluding isolated spaces that have negligible air exchange with the ventilated regions of the building
} 


\title{
Experimental Approach
}

\author{
Research Facility
}

Measurements were completed in a laboratory (Bauman and Arens 1988) called the Controlled Environment Chamber (CEC) which has dimensions of $5.5 \mathrm{~m}$ by $5.5 \mathrm{~m}$ by $2.5 \mathrm{~m}$ high. Although a flexible research laboratory, the CEC closely resembles a modern office space with two exterior and two interior walls. The CEC was subdivided into two work stations by $1.65 \mathrm{~m}$ high partitions (see Figure 1). Each work station contained a desk, a side table, a chair, and a seated mannequin that released heat in a manner similar to a real person. The CEC contained sources of heat and air motion typical of real offices including the heated mannequins, personal computers with small cooling fans plus monitors, a power supply for one of the mannequins, and a task light. To simulate heat loss to a cold exterior environment (or to simulate heat gain in cooling tests), cooled (or warmed) air was directed between the panes of exterior windows located in two walls. Natural convective air flow caused by the cool or warm windows was an additional source of indoor air motion.

Experiments were performed using three different air supply diffusers typical of those used in U.S. office buildings. Diffuser No. 1 was a basic rectangular $(61 \mathrm{~cm}$ by $61 \mathrm{~cm})$ perforated diffuser that directed supply air horizontally in four directions (perpendicular to each edge of the diffuser). The second diffuser was also a perforated unit with the same dimensions and air supply directions, but with an improved interior air deflector. Diffuser No. 3 was a linear diffuser with two parallel slots, $1.2 \mathrm{~m}$ long, with air directed perpendicular to slots horizontally in both directions. Experiments were performed with one and two linear slot diffusers. All diffusers and the rectangular $(61 \mathrm{~cm}$ by $61 \mathrm{~cm})$ return air grille were installed in the suspended ceiling. The locations of the return grille and diffusers in the ceiling of the CEC are indicated in Figure 1.

One commonly used indicator of the performance of a supply diffuser in distributing air is the throw, defined as the distance from the diffuser edge at which the peak velocity in the supply jet has decreased to a specified value (e.g., $0.25 \mathrm{~m} \mathrm{~s}^{-1}$ ). Based on the measurements of Bauman et al. (1995), the throws for our experiments varied by a factor of four.

\section{Matrix of Experimental Conditions}

Table 1 lists the experimental conditions. Experimental variables included the diffuser type, the supply flow rate of approximately 0.038 or $0.078 \mathrm{~m}^{3} \mathrm{~s}^{-1}\left(80 \mathrm{ft}^{3} \mathrm{~min}^{-1}\right.$ or $\left.165 \mathrm{ft}^{3} \mathrm{~min}^{-1}\right)$, and the percentage of outside air in the supply airstream. HVAC system flow rates were constant within a few percent during each test. Air flow rates were not varied during experiments because the tracer gas procedure for measuring ACE requires constant flow rates. To simulate the low supply flow rates of VAV systems when internal loads are small, supply flow rates per unit floor area were relatively low, approximately $2.6 \times 10^{-3} \mathrm{~m}^{3} \mathrm{~s}^{-1} \mathrm{~m}^{-2}$ or $1.2 \times 10^{-3} \mathrm{~m}^{3} \mathrm{~s}^{-1} \mathrm{~m}^{-2}(0.51$ or 0.25 $\left.\mathrm{ft}^{3} \mathrm{~min}^{-1} \mathrm{ft}^{-2}\right)$. Constant-volume ventilation systems commonly have a supply flow rate per unit floor area greater than approximately $3.5 \mathrm{~m}^{3} \mathrm{~s}^{-1} \mathrm{~m}^{-2}\left(0.7 \mathrm{ft}^{3} \min ^{-1} \mathrm{ft}^{-2}\right)$.

With the lower supply flow rate and two linear slot diffusers installed, the supply flow rate per diffuser was below the manufacturers recommended range (i.e., no throw data were 
available). All other experiments used supply flow rates for which diffuser performance data were available.

Most tests were performed with $100 \%$ outside air, a condition that would accentuate any short circuiting problems. In all tests without interior mixing fans, the internal heat generation was approximately $510 \mathrm{~W}$ distributed as indicated in Figure 1.

Nineteen tests were performed with heated supply air (heating tests). In four of these tests the supply temperature oscillated between approximately chamber air temperature and $20{ }^{\circ} \mathrm{C}$ above the chamber air temperature, similar to the oscillation with a thermostatic control system that turns the heat source on and off. In the remaining 15 heating tests, the supply air temperature was a constant $7{ }^{\circ} \mathrm{C}$ to $9^{\circ} \mathrm{C}$ above the chamber air temperature.

In five tests, the chamber required cooling. Warm air directed between the panes of exterior windows and the internal heat sources created the demand for cooling.

To add to existing data on measurement accuracy, two tests were performed with mixing fans in the CEC. The thorough mixing of indoor air should cause the ACE to equal unity, thus, measurement accuracy is indicated by the difference between unity and the measured values of ACE.

Measurement Procedures and Calculations

\section{Air Change Effectiveness}

ACE was measured using a tracer gas stepup procedure. After test conditions were established, sulfur hexafluoride $\left(\mathrm{SF}_{6}\right)$ tracer gas was injected at a constant rate (constant within $1 \%$ ) into the supply airstream. Mixing fans inside the HVAC system ductwork ensured thorough mixing of the tracer in the supply airstream. The thoroughness of mixing of the tracer in the supply air was confirmed through analyses of samples collected from multiple locations in the supply-air duct.

Using three gas chromatographs with electron capture detectors (GC-ECD), tracer gas concentrations were measured as a function of time during the period of concentration increase. Concentrations were measured approximately every four minutes at the following twelve locations: the outside air intake; the supply airstream both upstream and downstream of the point of tracer injection; the return/exhaust airstream; four breathing level locations $1.1 \mathrm{~m}$ above the floor within the workstations (two locations were approximately $0.3 \mathrm{~m}$ in front of the mannequins' noses); and four locations $2.1 \mathrm{~m}$ above the floor. The GC-ECD units were calibrated prior to each test with thirteen calibration gases.

Ages of air $(\tau)$ were determined from the $\mathrm{SF}_{6}$ tracer data via the equation

$$
\tau=\frac{1}{\mathrm{C}\left(\mathrm{t}_{\text {end }}\right)} \int_{0}^{\mathrm{t}_{\text {end }}}\left[\mathrm{C}\left(\mathrm{t}_{\text {end }}\right)-\mathrm{C}(\mathrm{t})\right] \mathrm{dt},
$$

where $C(t)$ is the tracer gas concentration at the point in question, $C\left(t_{e n d}\right)$ is the steady state concentration at the end of the stepup, and $t$ is the time elapsed since the start of tracer gas injection. The ACE was determined from

$$
A C E=\tau_{\text {return }} / \frac{}{\tau_{b l}}
$$


where $\tau_{\text {return }}$ is the age of the return/exhaust air and $\overline{\tau_{b l}}$ is the average age of air at the four breathing level measurement locations.

Pollutant Removal Efficiency

For the measurements of PRE, two different types of indoor pollutant sources were simulated with passive tracer gas emitters. Twelve emitters of metaperfluorodimethylcyclohexane $\left(\mathrm{C}_{8} \mathrm{~F}_{16}\right)$ tracer gas were placed on the floor, spaced approximately evenly, to simulate the emission of pollutants from the floor covering. Two emitters of perfluoromethylcyclohexane $\left(\mathrm{C}_{7} \mathrm{~F}_{14}\right)$ tracer gas were attached to each heated mannequin at the location of the armpits to simulate the emissions of body odors by occupants. To measure the concentrations of the $\mathrm{C}_{8} \mathrm{~F}_{16}$ and $\mathrm{C}_{7} \mathrm{~F}_{14}$ tracers, duplicate samples were collected from the breathing location of each mannequin and also from the return/exhaust airstream by drawing air at constant rates through sorbent tubes. The sorbent tubes were subsequently analyzed with a calibrated gas chromatograph-mass spectrometer (GCMS) system. The tracer emitters and analytical system have been described previously (Fisk et al. 1993).

The PRE for the floor covering source of pollutant, $P R E_{\text {floor }}$, was computed with the equation

$$
P R E_{\text {floor }}=\bar{C}_{\text {return }} / 1 / 2 \sum_{n=1}^{2} \bar{C}_{b l}^{n}
$$

where $\bar{C}$ is the time-average concentration of the $\mathrm{C}_{8} \mathrm{~F}_{16} 6$ tracer gas and the superscript $\mathrm{n}$ refers to the two breathing level locations of the mannequins.

For the simulated source of body odor, the breathing zone concentration varied considerably between breathing-level locations, therefore, values of $P R E_{b o}$ were based on the measured concentration at individual breathing level locations at mannequins, i.e.,

$$
P R E_{b o}^{n}=\bar{C}_{\text {return }} / \bar{C}_{b l}^{n}
$$

where the superscript $\mathrm{n}$ refers to the breathing level location of the mannequin in workstation 1 $(n=1)$ or workstation $2(n=2)$.

Our equations for PRE should not be used indiscriminately. If the pollutant was present in outdoor air, the PRE equations would need to be modified by subtracting the outdoor concentration from both the numerator and the denominator. If an air cleaning system removed the pollutant, these PRE definitions would be invalid.

\section{Percentage Outside Air:}

To determine the percentage outside air, tracer gas concentrations were monitored in the return/exhaust airstream and in the supply airstream downstream of the junction of the outside-air and supply-air ducts. To assure that the measured tracer gas concentrations were representative of the average concentrations in the airstreams, samples from multiple locations were analyzed for a range of operating conditions. The percentage outside air was determined from the equation: 


$$
\% O A=\left(1-C_{m} / C_{r}\right) 100 \%
$$

where $\mathrm{C}_{\mathrm{m}}$ is the concentration of tracer gas in the mixture of outside and recirculated air and $\mathrm{C}_{\mathrm{r}}$ is the concentration in the return/exhaust air.

\section{Flow Rates and Temperatures}

The flow rates of air in the HVAC system were measured using pitot tubes with a differental pressure transducer and the airstream temperatures were measured with thermisters. The measurement systems is described in greater detail elsewhere (Bauman et al. 1991, 1995 and Fisk et al. 1991). The throws of the air supply diffusers, the air velocities at the edges of the diffusers, and indoor thermal comfort conditions were measured for the same range of test conditions as described by Bauman et al. (1995).

\section{Regression Modeling}

Multivariate linear regression modeling was employed to better define the factors that influence ACE during the heating tests. Based on our understanding of the fluid dynamics, we constructed nine different multivariate models. Individual models contained three or fewer explanatory variables from the following list: supply diffuser type; supply air flow rate; steady versus oscillating supply air temperature; measured air velocity at the edge of the supply diffuser; percent outside air; difference between chamber temperature and temperature of air passed between the windows; Archimedes Number for supply air jet; and the inverse of the cube root of the mechanical power of the supply air jet. Some models were applied to a subset of the heating tests (e.g., those with low supply flow rates or those with $100 \%$ outside air). The selections of explanatory variables in each model were based on judgment, for example, supply air throw was used as a substitute for diffuser type and supply flow rate (which jointly determine throw).

A few of the explanatory variables used in the multivariate linear regression modeling require further explanation. The Archimedes Number (Ar) of the supply air jet is a commonly used dimensionless number for characterizing jets of fluid. It is a ratio of buoyancy forces to inertial forces. As Ar increases, buoyancy forces, which are a function of the difference between supply air temperature and room air temperature, should have a larger impact on indoor air motion and ACE. Calculation of Ar requires a temperature difference, a characteristic length, and a velocity. The temperature difference is the difference between supply air temperature just inside the diffuser and room temperature. For the complex supply diffusers of this study, there is no clear best choice for characteristic length and velocity. For the characteristic length, we used the length of the side of the rectangular diffusers and the thickness of the slots in the slot diffuser. For velocity, we used both the measured velocity at the edge of the diffuser (Bauman et al. 1995) and the supply flow rate divided by the exit area of the diffuser.

The inverse of the cube root of the mechanical power of the supply air jet is the other explanatory variable that requires explanation. In a study by Drescher et al. (1995) this parameter was a good predictor of the time required for a pollutant to mix to a nearly uniform concentration after an instantaneous release of the pollutant at a single point. Hence, this parameter was also considered a potential explanatory variable for ACE. We calculated this parameter with the expression 


$$
P^{-\frac{1}{3}}=\left(0.5 \rho V^{3} A\right)^{-\frac{1}{3}}
$$

where $\rho$ is the supply air density, $\mathrm{V}$ is the supply air velocity, and $\mathrm{A}$ is the exit area of the diffuser. Again, for velocity we used both the measured velocity at the edge of the diffuser and the supply flow rate divided by the exit area of the diffuser.

\section{Results}

Air Change Effectiveness

In the two tests with the indoor air vigorously mixed with fans, the measured ACE values were 0.99 and 1.03. The expected true value of ACE, when the air is thoroughly mixed, is unity. The small differences between these measured values and unity suggest that the measurement uncertainty for ACE is low. Based on these results and the results of nine previous "well-mixed" tests within the $\mathrm{CEC}$, the estimated $95 \%$ confidence limits are $1.00 \pm 0.02$. (Larger uncertainties are expected in field studies.) In the subsequent discussion, $95 \%$ confidence limits of \pm 0.02 from the measured value are assumed for all measured values of ACE.

Figure 2 illustrates the results of all the ACE measurements. The ACE was more strongly influenced by the test variable of heating versus cooling than by any other variable. In the nineteen heating tests, the ACE ranged from 0.69 to 0.91 (mean $=0.81$ ). In every heating test, the ACE is significantly less than unity, given the estimated $95 \%$ confidence limits. In cooling tests, the ACE ranged from 0.99 to 1.15 (mean =1.08). In four of five of these cooling tests, the ACE was significantly greater than unity.

Referring to the results in Table 1, other factors appeared to have a more modest, but still statistically significant influence on ACE. Recirculation of air by the HVAC system in four of the tests with heating was associated with higher values of ACE, ranging from 0.81 to 0.91 $($ mean $=0.88)$. In two pairs of tests with and without recirculation (Test 113 versus Test 115 and Test 118 versus Test 121), the recirculation was associated with an increase of 0.05 in ACE. In contrast to the common expectation of a higher supply air flow rate inducing greater mixing of the indoor air leading to a higher ACE, higher supply flow rates appeared to be associated with lower values of ACE. Use of a single linear slot diffuser resulted in a significantly higher ACE for the heating tests with the higher supply air flow rate, compared to the other supply diffuser options.

Some test variables did not appear to influence ACE in a consistent and statistically significant manner. An oscillating supply temperature during heating tests, compared to a steady supply temperature, did not have a consistent impact on ACE. When tests were sorted by the measured supply air throw (neglecting diffuser type), there was no clearly-evident relationship between throw and ACE.

In the multivariate linear regression modeling utilized to better define the factors that influence ACE during the heating tests, six potential explanatory variables were found to be significant predictors (based on $\mathrm{p} \leq 0.1$ ) of ACE in one or more models. These significant variables were: diffuser type $3 b$ (i.e., single linear slot diffuser) with diffuser type 1 as the reference case; supply flow rate; supply air velocity (see Bauman et al. 1995), percent outside air; inverse of the cube root of the mechanical power of the supply air jet (as defined in equation 6); 
and difference between chamber temperature and temperature of air passed between the windows. These findings are consistent with our previous comments based on reviews of plots of the data. The model with the best fit for the full set of 19 heating tests had an $\mathrm{R}^{2}$ of 0.74 with the following significant explanatory variables: diffuser type $3 b(p=0.01)$; supply flow rate $(\mathrm{p}=0.01)$; and percentage outside air $(\mathrm{p}=0.13)$.

\section{Pollutant Removal Efficiency}

PRE was measured in only five tests. (Data from two additional tests were rejected because the PFT concentrations from a duplicate sample differed by more than $20 \%$.) We have limited information on the accuracy of the PRE measurements. The 28 duplicate measurements of tracer gas concentrations from the five tests provide some information on measurement precision. The average discrepancy between tracer gas concentrations computed from duplicate samples was 7\%. The 95\% confidence limits for this discrepancy are 5\% to $8 \%$. Since the PRE is a ratio of two measured concentrations, using a propagation of error analysis, the $95 \%$ confidence interval for the repeatability in the PRE measurement is approximately $7 \%$ to $11 \%$.

$\mathrm{PRE}_{\text {floor }}$ ranged from 0.63 to 0.82 (mean $=0.72$ ) in the three heating tests and was 1.00 and 1.13 in the two cooling tests. Given the limited number of data points, an examination of the relationship between $\mathrm{PRE}_{\text {floor }}$ and other test variables is inappropriate. In a linear regression (Figure 3$), \mathrm{PRE}_{\text {floor }}$ was strongly correlated with $\mathrm{ACE}\left(\mathrm{R}^{2}=0.98\right)$ and the values of $P R E_{\text {floor }}$ were within approximately 0.1 of the values of ACE.

$\mathrm{PRE}_{\mathrm{bo}}$ ranged widely from 0.46 to 1.18 and varied between workstations as well as between tests. In workstation $1, \mathrm{PRE}_{\mathrm{bo}}$ was always slightly greater than unity while in workstation $2 \mathrm{PRE}_{\mathrm{bo}}$ was always smaller than unity. PRE $\mathrm{Po}_{\mathrm{b}}$ was not well correlated with ACE. In many cases, numerical values of $\mathrm{PRE}_{\mathrm{bo}}$ were quite different from values of ACE. The slope of the linear regression curve (not shown) between $\mathrm{PRE}_{\mathrm{bo}}$ for workstation 1 and ACE was negative $\left(\mathrm{PRE}_{\mathrm{bo}}\right.$ decreased as $\mathrm{ACE}$ increased) and the correlation was very weak $\left(\mathrm{R}^{2}=0.43\right)$. For workstation 2, the slope of the regression curve (not shown) was positive with a fair correlation $\left(\mathrm{R}^{2}=0.76\right)$.

\section{Discussion}

A primary objective of this study was to determine the ACE in adverse, but still realistic, conditions. In fifteen tests with heated supply air supplied at relatively low volumetric flow rates, 100\% outside air, and three typical supply diffusers (including a very basic unit), the ACE ranged from 0.69 to 0.89 . In four previous laboratory tests with heating and $100 \%$ outside air, the ACE ranged from approximately 0.7 to 0.9 (Fisk and Faulkner 1992). Two prior ACE measurements by Offermann (1988) with heating and 33\% outside air yielded values of 0.66 and 0.73. (We have not considered additional data by Offermann for very atypical test conditions such as no supply diffusers.) These results suggest that significant short circuiting can occur under these adverse conditions. However, short circuiting is of greatest concern when outside air ventilation rates are low. In U.S. buildings, low outside air ventilation rates generally occur when the HVAC system recirculates air. In our tests with heating and recirculation (40\% to $60 \%$ outside air), the ACE ranged from 0.81 to 0.91 . Greater recirculation would be expected to bring 
the ACE closer to unity. These values of ACE, with and without recirculation, should be usable as approximate lower limits for ACE.

As in most previous studies (e.g., Fisk and Faulkner 1992; Persily 1986; Persily and Dols 1989; Seppanen 1986; Olesen and Seelen 1992), the ACE was near unity when the supply air was cooled. Hence, this study provides further evidence that short circuiting is rarely a problem when the building is being cooled via the supply air.

The choice between heating and cooling had the largest impact on ACE with lower values of ACE in the heating tests. Recirculation of air by the HVAC system (compared to $100 \%$ outside air), the lower supply flow rate (compared to the higher rate), and use of a single linear slot diffuser (compared to a basic rectangular diffuser) were associated with slightly to moderately higher values of ACE.

The association of higher ACE with lower supply flow rates might be unexpected since lower supply flow rates should yield less indoor air mixing driven by the supply air jet. One potential explanation is as follows. The uniformity of age of air in a ventilated space will increase with the total rate of mixing, driven by convective air motion along walls, thermal plumes, the supply air jet and other factors. The supply jet may not be the dominant source of mixing. The introduction of outside air, which has an age of zero, tends to decrease the uniformity of age of air. When the rate of outside air supply decreases, the total rate of mixing per unit volume of outside air supply can increase, resulting in an ACE closer to unity.

One important, but expected, finding of this study is that the ACE is strongly correlated with $\mathrm{PRE}_{\text {floor }}$ the pollutant removal efficiency for a passively-emitted, spatially-distributed source of pollutants. If this were not true, one would have to question the value of measurements of ACE and similar parameters that indicate indoor airflow patterns. Such parameters are valuable only if they indicate, at least approximately, the efficiency of the ventilation process in controlling occupants' exposures to air pollutants. Further experiments should be completed to confirm the strong correlation between ACE and PRE floor.

The pollutant removal efficiency for the body odor source varied by as much as a factor of two between workstations. For workstation 2, $\mathrm{PRE}_{\mathrm{bo}}$ ranged from 1.03 to 1.18; hence the exposure of the mannequin to the simulated body odor pollutant was slightly lower than would occur in the case of perfect mixing. For workstation $1, \mathrm{PRE}_{\mathrm{bo}}$ ranged from 0.46 to 0.91 ; thus, the mannequin was exposed to the simulated body odor pollutant at a concentration that was considerably higher than would occur with perfect mixing. We can only speculate about the explanation for this large difference in $\mathrm{PRE}_{\mathrm{bo}}$ between workstations. The mannequins were of different design and thus varied slightly with respect to geometry and the spatial distribution of heat output. The computer and power supply on the desk in workstation 1 used to control the thermal mannequin (see Bauman et al. 1995) generated considerable heat that may have affected the nearby indoor air and pollutant flow patterns. Workstation 1 was also closer to the exterior windows--a source of air motion. When the pollutant source is spatially concentrated and located near the breathing location, small changes in indoor air flows may substantially impact pollutant concentrations at breathing locations.

The measurements of PRE were based on samples collected $0.3 \mathrm{~m}$ in front of the mannequins' noses. We are not certain if such sample locations are optimal for indicating exposure. Possibly, actual people inhale air from a region of boundary layer air flow closer to the body. Alternately, peoples' frequent movements and the inhalation and exhalation process may cause the inhaled air to be a mixture of air from a larger spatial region near the head. Further 
experiments are needed to better define the optimal sample collection location for measurement of PRE.

This study also illustrates a limitation of the ACE parameter. The ACE is not a good surrogate for $\mathrm{PRE}_{\mathrm{bo}}$, the pollutant removal efficiency for the simulated body-odor pollutant. Considering this limitation of the ACE and considering the many complications and restrictions associated with ACE measurements (Fisk and Faulkner 1992, Fisk et al. 1993), greater attention should be placed on pollutant removal efficiencies. The PREs are more direct indicators of the efficiency of pollutant removal than ACEs and PREs can be measured in a wider variety of buildings, such as those with unsteady outside air supply rates and large numbers of air handlers. A small set of PRE parameters may be more valuable and easier to measure than the ACE.

\section{Conclusions}

Our experimental results provide evidence of significant short circuiting of ventilation air between supply diffusers and return grills under adverse operating conditions of heated supply air, supply air flow rates typical of the minimum supply flow rates of VAV ventilation systems, and $100 \%$ outside air. Recirculation of air by the air handler reduces the significance of the short-circuiting.

The study results indicate that short circuiting was not a problem when the test space was cooled via the supply air. Most prior laboratory and field studies also indicate that short circuiting is not a problem when the building is being cooled and supply-air is delivered with a high velocity through induction-type diffusers.

The ACE was strongly correlated with $\mathrm{PRE}_{\text {floor }}$ the pollutant removal efficiency for a passive, spatially-distributed source of pollutants. Assuming that additional measurements confirm this correlation, the ACE can be considered a valuable indicator of the efficiency of the ventilation process in controlling occupants' exposures to air pollutants with this type of source. However, this study illustrates that the $\mathrm{ACE}$ is not a good surrogate for $\mathrm{PRE}_{\mathrm{bo}}$, the pollutant removal efficiency for the simulated body-odor pollutant.

\section{Acknowledgments}

We appreciate the assistance of Dan IntHout, Titus Products, for technical advice and for reviewing a draft of this paper. We also appreciate comments on the draft by Ashok Gadgil and Leon Alevantis. This work was supported by the Assistant Secretary for Energy Efficiency and Renewable Energy, Office of Building Technologies, Building Systems and Materials Division of the U.S. Department of Energy (DOE) under contract No. DE-AC03-76SF00098. 


\section{References}

ASHRAE (1992) "Standard method of measuring air change effectiveness: public review draft", American Society of Heating, Refrigerating, and Air Conditioning Engineers, Inc., Atlanta.

Bauman, F.S. and Arens, E.A. (1988) "The development of a controlled-environment chamber for the physical and subjective assessment of human comfort in office environments", In: Kroner, W. (ed.), Proceedings of the International Symposium on Advanced Comfort Systems, A New Frontier: Environments for Innovation, Renssalaer Polytechnic Institute, Troy, NY, pp. 277-284.

Bauman, F.S., Faulkner, D., Arens, E.A., Fisk, W.J., Johnston, L.P., McNeel, P.J., Pih, D., and Zhang, H. (1991) "Air Movement, Comfort and Ventilation in Workstations." Lawrence Berkeley Laboratory Report, LBL-30574, Berkeley, CA.

Bauman, F.S., Huizenga, C., Xu, T., and Akimoto, T. (1995) "Thermal comfort with a variable air volume (VAV) system", Center for Environmental Design Research, University of California, Berkeley, California.

Drescher, A.C., Lobascio, C., Gadgil, A.J., and Nazaroff, W.W. (1995) "Mixing of a point source indoor pollutant by forced convection", Environmental Engineering Program, University of California, Berkeley, submitted to Indoor Air.

Fisk, W.J. and Faulkner, D. (1992). "Air exchange effectiveness in office buildings: measurement techniques and results." In: Murakami, S., Kaizuka, M., Yoshino, H., and Kato, S. (eds.), Proceedings of the 1992 International Symposium on Room Air Convection and Ventilation Effectiveness, Tokyo, pp. 213-223, published by ASHRAE, Atlanta.

Fisk, W.J., Faulkner, D., and Hodgson, A.T. (1993) "The pollutant control index: a new method of characterizing ventilation in commercial buildings", In: Seppanen, O., Ilmarinen, R., Jaakkola, J.J.K., Kukkonen, E., Sateri, J., and Vuorelma, H. (eds.) Proceedings of Indoor Air'93: The 6th International Conference on Indoor Air Quality and Climate, Helsinki, vol. 5, pp. 9-14,. Published by Indoor Air'93.

Fisk, W.J., Faulkner, D., Pih D., McNeel, P.J., Bauman, F.S., and Arens, E.A. (1991) "Indoor air flow and pollutant removal in a room with task ventilation", Indoor Air 1 (3), 247 - 262.

Offermann, F.J. (1988) "Ventilation effectiveness and ADPI measurements of a forced air heating system" ASHRAE Transactions 94(1), pp. 694-704.

Olesen, B.W. and Seelen, J. (1992) "Field measurements of air change effectiveness using tracer gas techniques”, In: IAQ'92, Environments for People, pp. 301-308, Published by ASHRAE, Atlanta. 
Persily, A.K. (1986) "Ventilation effectiveness measurements in an office building", In: Proceedings of IAQ'86, Managing Indoor Air for Health and Energy Conservation, pp. 548-567. Published by ASHRAE, Atlanta, GA.

Persily, A.K. and Dols, W.S. (1989) "Field measurements of ventilation and ventilation effectiveness in an office/library building", Indoor Air 1(3), pp. 229-246.

Sandberg, M. and Sjoberg, M. (1983) "The use of moments for assessing air quality in ventilated rooms", Buildings and Environment, 18, pp. 181-197.

Seppanen, O. (1986) "Ventilation efficiency in practice", In: Proceedings of IAQ'86, Managing Indoor Air for Health and Energy Conservation, pp. 559-567. Published by ASHRAE, Atlanta, GA. 
Table 1. Experimental conditions and primary measurement results.

\begin{tabular}{|c|c|c|c|c|c|c|c|c|c|c|c|c|c|}
\hline Test No. & $\begin{array}{c}\text { Dif- } \\
\text { fuser* }\end{array}$ & $\begin{array}{c}\% \\
\mathrm{OA}\end{array}$ & $\begin{array}{l}\text { Supply } \\
\text { Flow } \\
\text { Rate } \\
\left(\mathrm{m}^{3} \mathrm{~s}^{-1}\right)\end{array}$ & $\begin{array}{c}\text { Supply } \\
\text { Temp. } \\
\text { Minus } \\
\text { Chamber } \\
\text { Temp. } \\
\left({ }^{\circ} \mathrm{C}\right)\end{array}$ & $\begin{array}{l}\text { Supply } \\
\text { Temp, } \\
\text { Steady } \\
\text { vs. } \\
\text { Oscil- } \\
\text { lating }\end{array}$ & $\begin{array}{l}\text { Chamber } \\
\text { Temp. } \\
\text { minus } \\
\text { Window } \\
\text { Temp. } \\
\left({ }^{\circ} \mathrm{C}\right)\end{array}$ & $\begin{array}{c}\text { Cham- } \\
\text { ber } \\
\text { Temp. } \\
\left({ }^{\circ} \mathrm{C}\right)\end{array}$ & $\begin{array}{c}\text { Sup- } \\
\text { ply } \\
\text { Air } \\
\text { Throw }^{\dagger} \\
\text { (m) }\end{array}$ & $\begin{array}{c}\text { Supply } \\
\text { Air } \\
\text { Velo- } \\
\text { city }^{\ddagger} \\
\left(\mathrm{m} \mathrm{s}^{-1}\right)\end{array}$ & $\begin{array}{c}\text { Air } \\
\text { Change } \\
\text { Effec- } \\
\text { tive- } \\
\text { ness }\end{array}$ & $\begin{array}{c}\text { PRE } \\
\text { (floor) }\end{array}$ & $\begin{array}{c}\text { Work- } \\
\text { station } \\
1 \\
\text { PRE } \\
\text { (body } \\
\text { odor) }\end{array}$ & $\begin{array}{c}\text { Work- } \\
\text { station } \\
2 \\
\text { PRE } \\
\text { (body } \\
\text { odor) }\end{array}$ \\
\hline $96 \mathrm{M}^{* *}$ & 1 & 100 & 0.083 & 7 & Steady & 13 & 23 & 2.8 & 1.26 & 1.03 & & & \\
\hline $108 \mathrm{M}^{* *}$ & 2 & 100 & 0.038 & 8 & Steady & 9 & 24 & 1.2 & 0.46 & 0.99 & & & \\
\hline 101 & 1 & 100 & 0.035 & -12 & Steady & -11 & 27 & 1.7 & 0.68 & 1.15 & 1.13 & 0.91 & 1.07 \\
\hline 97 & 1 & 100 & 0.036 & 8 & Steady & 13 & 23 & 1.7 & 0.68 & 0.79 & & & \\
\hline 102 & 1 & 100 & 0.037 & -10 & Steady & -3 & 23 & 1.7 & 0.68 & 1.11 & & & \\
\hline 100 & 1 & 100 & 0.078 & -3 to +15 & Oscillate & 13 & 25 & 2.8 & 1.26 & 0.77 & 0.70 & 0.46 & 1.18 \\
\hline 93 & 1 & 100 & 0.082 & 8 & Steady & 14 & 24 & 2.8 & 1.26 & 0.74 & & & \\
\hline 99 & 1 & 62 & 0.039 & 7 & Steady & 10 & 25 & 1.7 & 0.68 & 0.81 & & & \\
\hline 109 & 2 & 100 & 0.036 & 7 & Steady & 10 & 25 & 1.2 & 0.46 & 0.87 & & & \\
\hline 106 & 2 & 100 & 0.037 & -13 & Steady & -3 & 26 & 1.2 & 0.46 & 1.09 & & & \\
\hline 105 & 2 & 100 & 0.040 & 7 & Steady & 10 & 25 & 1.2 & 0.46 & 0.80 & & & \\
\hline 104 & 2 & 100 & 0.075 & 9 & Steady & 13 & 24 & 2.7 & 0.96 & 0.70 & & & \\
\hline 107 & 2 & 100 & 0.080 & -1 to +22 & Oscillate & 14 & 25 & 2.7 & 0.96 & 0.76 & & & \\
\hline 110 & 2 & 59 & 0.039 & 7 & Steady & 10 & 25 & 1.2 & 0.46 & 0.90 & & & \\
\hline 114 & $3 a$ & 100 & 0.039 & -11 & Steady & -1 & 24 & 0.7 & 0.90 & 1.03 & 1.00 & 0.62 & 1.03 \\
\hline 113 & $3 a$ & 100 & 0.040 & 8 & Steady & 9 & 24 & 0.7 & 0.90 & 0.83 & 0.82 & 0.67 & 1.09 \\
\hline 111 & $3 a$ & 100 & 0.074 & 8 & Steady & 14 & 25 & 1.2 & 1.15 & 0.72 & & & \\
\hline 112 & $3 a$ & 100 & 0.076 & 9 & Steady & 14 & 24 & 1.2 & 1.15 & 0.74 & 0.63 & 0.47 & 1.1 \\
\hline 116 & $3 a$ & 100 & 0.078 & -1 to +22 & Oscillate & 14 & 25 & 1.2 & 1.15 & 0.69 & & & \\
\hline 115 & $3 a$ & 51 & 0.038 & 7 & Steady & 10 & 25 & 0.7 & 0.90 & 0.88 & & & \\
\hline 118 & $3 b$ & 100 & 0.038 & 8 & Steady & 10 & 25 & 1.2 & 1.15 & 0.86 & & & \\
\hline 119 & $3 b$ & 100 & 0.039 & -12 & Steady & -3 & 25 & 1.2 & 1.15 & 0.99 & & & \\
\hline 122 & $3 b$ & 100 & 0.078 & 7 & Steady & 11 & 26 & 2.2 & 1.47 & 0.83 & & & \\
\hline 120 & $3 b$ & 100 & 0.079 & -2 to +23 & Oscillate & 15 & 24 & 2.2 & 1.47 & 0.89 & & & \\
\hline 117 & $3 b$ & 100 & 0.079 & 8 & Steady & 15 & 24 & 2.2 & 1.47 & 0.83 & & & \\
\hline 121 & $3 b$ & 40 & 0.038 & 7 & Steady & 9 & 24 & 1.2 & 1.15 & 0.91 & & & \\
\hline
\end{tabular}

*3a designates two linear slot diffusers, $3 \mathrm{~b}$ designates a single linear slot diffuser

${ }^{\dagger}$ measured for isothermal conditions, see Bauman et al. (1995)

${ }^{\ddagger}$ measured at edge of diffuser, see Bauman et al. (1995)

** $\mathrm{M}$ indicates a test with mixing fans operating inside the ventilated room 


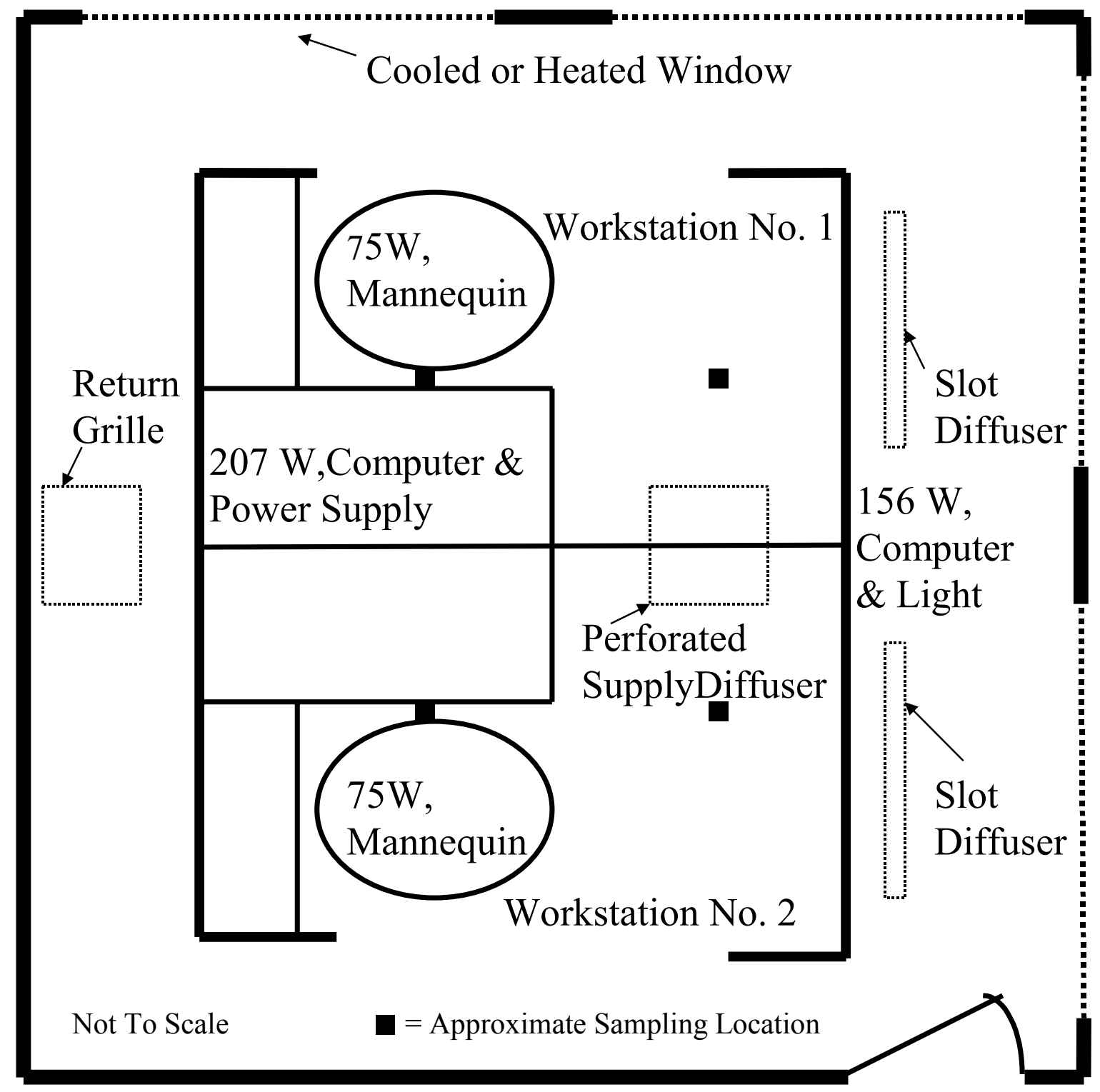

Figure 1. Plan view of Controlled Environment Chamber, illustrating locations of furnishings and internal heat sources. The locations of air supply diffusers and return grilles in the suspended ceiling of the Controlled Environment Chamber are also shown. When a single linear slot diffuser was used it was at the location adjacent to Workstation 1. 


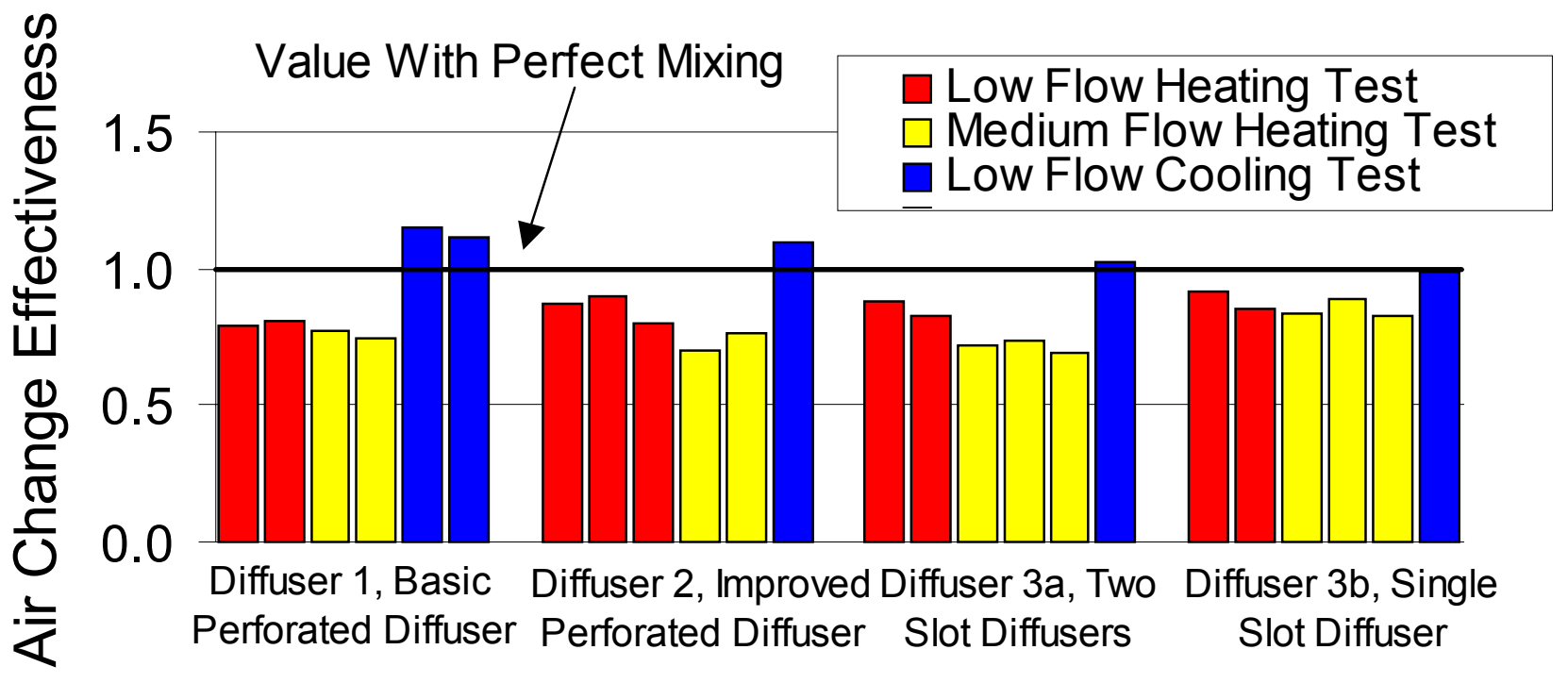

Figure 2. Measured air change effectiveness grouped by diffuser type. 


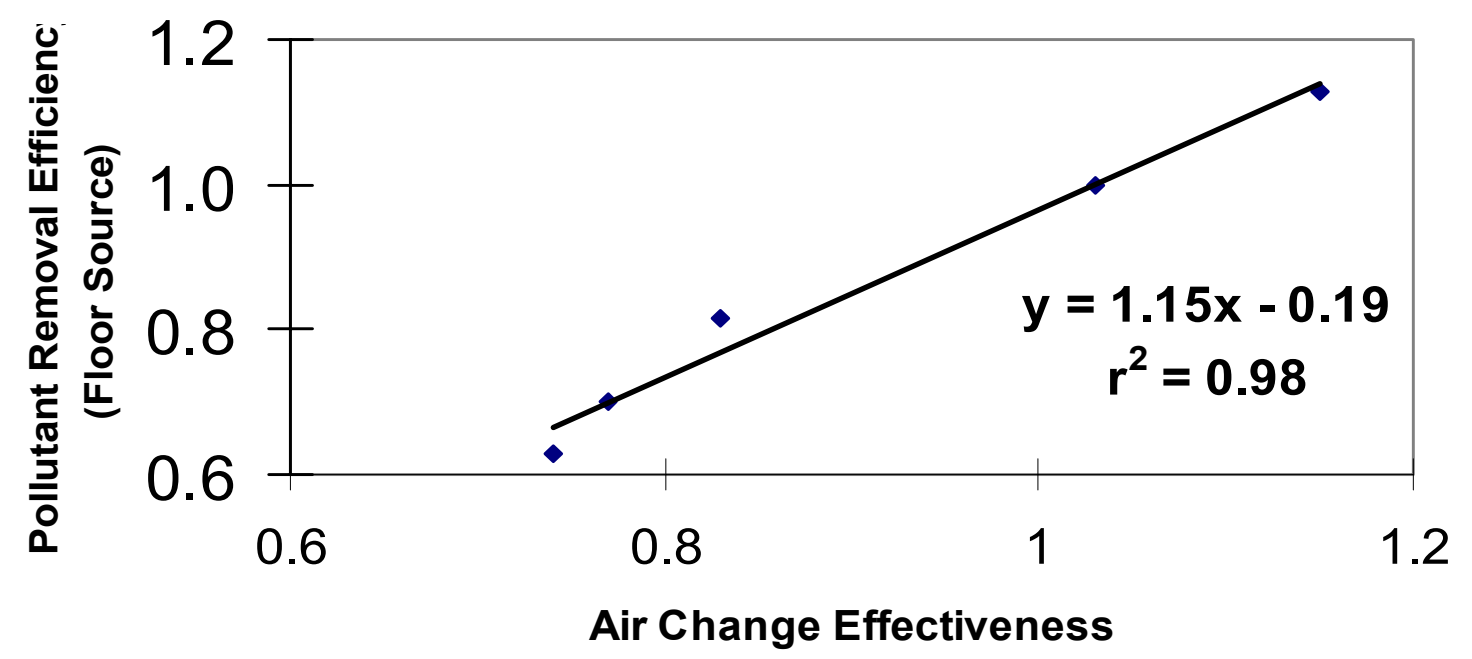

Figure 3. Pollutant removal efficiency for simulated pollutant emissions from floor covering plotted versus air change effectiveness. 